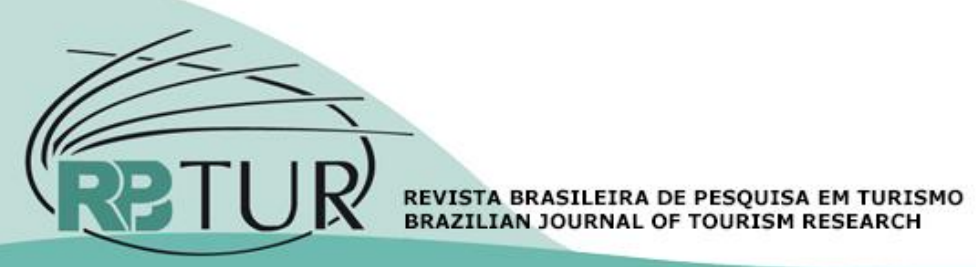

\title{
Artigos
}

\section{A viagem que mais contribuiu para quem eu sou: explorando as dimensões da Experiência Turística Eudaimônica}

\section{The most important trip for who I am: exploring the dimensions of the Eudaimonic Tourist Experience}

\section{El viaje que más contribuyó a quien yo soy: explorando las dimensiones de la Experiencia Turística Eudaimónica}

\author{
Sandro Alves de Medeiros 1; Márcio Augusto Gonçalves²; Ricardo Teixeira Veiga2; Giovana Barbosa Caraciolo 3 \\ 1 Universidade Federal de Alagoas (UFAL), Penedo, Brasil; \\ 2 Universidade Federal de Minas Gerais (UFMG), Belo Horizonte, Brasil; \\ 3 Ministério da Agricultura, Maceió, Alagoas, Brasil.
}

Palavras-chave:

Experiência turística Eudaimonia;

Psicologia positiva.

Keywords:

Tourist experience;

Eudaimonia;

Positive psychology.
Resumo

Com base em uma revisão do conceito de eudaimonia, o estudo propõe uma definição para o constructo experiência turística eudaimônica e identifica 15 potenciais dimensões constituintes do constructo, a partir de uma extensa revisão da literatura nos domínios da psicologia positiva, psicologia existencial-humanista, psicologia do desenvolvimento (estudos sobre a formação da identidade na linha Eriksoniana) e do turismo (estudos sobre experiência turística transformadora). Com o objetivo de validar as dimensões teorizadas, um levantamento com 569 sujeitos foi empreendido e a análise fatorial exploratória sobre os dados extraiu seis fatores (Alteridade e Benevolência, Intimidade e Pertencimento, Significância pessoal, Abertura ao novo, Autonomia e Amadurecimento) que explicaram $62,636 \%$ da variância total. Com forte fundamentação teórica e empírica, o estudo buscou contribuir com o entendimento dos processos transformativos proporcionados pelas experiências turísticas, fornecendo uma estrutura multidimensional para experiências eudaimônicas em contextos turísticos.

Abstract

Based on a review of the concept of eudaimonia, the study proposes a definition for the eudaimonic tourist experience construct and identifies 15 potential constituent dimensions of the construct, from an extensive literature review in the domains of positive psychology, existential-humanistic psychology, developmental psychology (studies on identity formation in the Eriksonian stream) and tourism (studies on transformative tourism experience). In order to validate the theorized dimensions, a survey with 569 subjects was undertaken. The results of the exploratory factor analysis revealed six factors (Alterity and Benevolence, Intimacy and Belonging, Personal meaningfulness, Openness to the new, Autonomy and Maturity), which accounted for $62.636 \%$ of the total variance. Through strong theoretical and empirical foundation, the study aimed to contribute to the understanding of the transformative processes provided by tourist experiences, proposing a multidimensional structure for eudaimonic experiences in tourism contexts. 
Palavras clave:

Experiencia turística;

Eudemonía;

Psicología positiva.

Revisado por pares.

Recebido em: 21/01/2019.

Aprovado em: 23/03/2019.

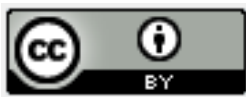

Resumen

Com base en una revisión del concepto de eudaimonía, el estudio propone una definición para el constructo experiencia turística eudaimónica e identifica 15 potenciales dimensiones constituyentes del constructo, a partir de una extensa revisión de la literatura en los ámbitos de la psicología positiva, psicología existencial-humanista, psicología del desarrollo (estudios sobre la formación de la identidad en la línea Eriksoniana) y del turismo (estudios sobre la experiencia turística transformadora). Con el objetivo de validar las dimensiones teorizadas, una encuesta con 569 sujetos es emprendida y el análisis factorial exploratorio sobre los datos extrajo seis factores (Alteridad y Benevolencia, Intimidad y Pertenencia, Significación personal, Apertura al nuevo, Autonomía y maduración) que explicaron el 62,636\% de la varianza total. Com fuerte fundamentación teórica y empírica, el estudio buscó contribuir con el entendimiento de los procesos transformativos proporcionados por las experiencias turísticas, proporcionando una estructura multidimensional para experiencias eudaimónicas en contextos turísticos.

Como citar: Medeiros, S. A., et al. (2020). A viagem que mais contribuiu para quem eu sou: explorando as dimensões da Experiência Turística Eudaimônica. Revista Brasileira de Pesquisa em Turismo, São Paulo, 14 (1), p. 14-33, jan./abr. http://dx.doi.org/10.7784/rbtur.v14i1.1599

\section{INTRODUÇÃO}

Pesquisas que mostram a experiência turística como uma jornada de autodescoberta ou um processo de autoconhecimento e os impactos que as reflexões suscitadas em condições de liminaridade provocam nas concepções que os indivíduos possuem sobre si próprios e sobre sua realidade são abundantes na literatura (Kontogeorgopoulos, 2017, Kirillova, Lehto e Cai, 2016a, Coghlan e Weiler, 2015, Lean, Staiff, e Waterton, 2014, Voigt, Brown, e Howat, 2011, Wearing, Stevenson, e Young, 2010, Andrews, 2009, Noy, 2004). Nesses estudos, a experiência turística é assumida como um processo que deflagra transformações pessoais, levando a redefinições na autoidentidade.

Wearing, Stevenson e Young (2010, p. 36), por exemplo, entendem o turismo como um “processo de interação social estendida, no qual a autoidentidade tem o potencial de expansão e crescimento por meio do engajamento do turista com outros ambientes, povos, sociedades e culturas". Desforges (2000) sustenta que as viagens possibilitam a reflexão e podem fornecer uma série de respostas a perguntas sobre a autoidentidade. Para Neumann (1992, p.179), "as viagens proporcionam a oportunidade de adquirir experiências que se tornam a base para a produção de identidade e são reveladas através das narrativas que emergem de experiências de viagem".

A formação da identidade resulta de dois processos, o da descoberta e o da criação (Waterman, 1984). No primeiro, algo que preexiste ao indivíduo, seu eu verdadeiro, precisa ser "descoberto". No segundo, o indivíduo nasce sem um eu verdadeiro, mas sua identidade vai sendo construída em um processo contínuo de escolhas feitas pelo próprio indivíduo, dentre as ilimitadas possibilidades que se lhes apresentam. A metáfora da autodescoberta baseia-se principalmente nos filósofos da antiga Grécia. A famosa frase atribuída a Sócrates - Conhece-te a ti mesmo - mas correspondente a uma inscrição apócrifa do templo de Apolo em Delphos, resume o fundamento desse paradigma. Por outro lado, a metáfora da criação alicerçase principalmente na filosofia existencialista de Jean-Paul Sartre (Waterman, 1984).

Waterman (Waterman, Schwartz, e Conti, 2008, Waterman, 2004, 1993, 1990) sugere que o desenvolvimento da identidade terá maiores chances de prosseguir com sucesso quando o indivíduo puder identificar seus melhores potenciais e se envolver em atividades que o levem a realizá-los. 0 autor afirma que esse reconhecimento das próprias potencialidades acontece durante experiências que possibilitem ao indivíduo sentimentos de expressividade pessoal, as quais ele chamou de experiências eudaimônicas, resgatando um termo [eudaimonia] da Grécia antiga associado a Aristóteles, que o relaciona ao supremo bem, muitas vezes traduzido como felicidade ou eu verdadeiro.

A ideia de experiência eudaimônica tem inspirado muitos estudos no campo do turismo nos últimos anos (Kirillova, Lehto, e Cai, 2017, Filep, Laing, e Csikszentmihalyi, 2017, Knoblock, Robertson, e Aitken, 2016, 
Matteucci e Filep, 2015, Alexander e Bakir, 2013, Filep e Deery, 2010, Voigt, Howat e Brown, 2010). Essas pesquisas utilizam os conceitos e teorias do emergente campo da psicologia positiva para estudar a experiência turística como facilitadora do crescimento interior e evocadora das componentes do bem-estar e do florescimento humano - emoções positivas, engajamento em atividades significativas, relacionamentos positivos, significado e propósito na vida e autorrealização - traduzidos pelo acrônimo PERMA [Positive emotions, Engagement, Relationship, Meaning e Achievement] (Filep e Pearce, 2013, Seligman, 2011).

Ainda que esses estudos abordem a experiência turística como vetor para o bem-estar e para o desenvolvimento do self, eles exploram de maneira diferente os diversos aspectos da experiência eudaimônica, além de darem pouca ênfase à questão da autodescoberta, que subjaz ao conceito de eudaimonia, a busca do eu verdadeiro. Essa premissa fundamenta a orientação de Waterman (Waterman, Schwartz, e Conti, 2008, Waterman, 2004) de que as resoluções mais bem-sucedidas da autoidentidade são aquelas decorrentes dos processos de autodescoberta, com a identificação e o desenvolvimento dos talentos e habilidades que representam os melhores potenciais individuais, diretamente relacionados a compromissos pessoalmente significativos (Waterman, Schwartz, Zamboanga, Ravert, Williams, Agocha, Kim, e Donnellan, 2010).

Assim, conhecer quais os aspectos mais significativos do desenvolvimento pessoal são proporcionados por experiências de viagem se mostra como de vital importância para a compreensão mais completa dos processos transformativos proporcionados pelo turismo. Uma busca com os termos "eudaimonia" e "turismo", em português e inglês, nas bases EBSCO, SciELO e Spell, para o intervalo compreendido entre 2008 e 2018, não localizou estudos que demonstrassem uma estrutura dimensional para a experiência eudaimônica em ambientes turísticos. Os estudos quantitativos encontrados abordavam a eudaimonia aproximando-a pelo constructo bem-estar (subjetivo ou psicológico) ou sob a temática da qualidade de vida. Ao que tudo leva a crer, parece existir uma lacuna na literatura relacionada à estruturação conceitual e empírica para o constructo experiência turística eudaimônica.

Dessa forma, o presente estudo se propôs a contribuir com o preenchimento dessa lacuna, guiando-se pela seguinte questão: que aspectos do desenvolvimento pessoal são percebidos por pessoas em viagens consideradas significativas para a definição de quem elas são no atual momento de suas vidas?

A fim de responder essa questão, três objetivos foram estabelecidos: (1) elaborar uma definição para o constructo experiência turística eudaimônica a partir do entendimento da ideia de eudaimonia; (2) identificar na literatura as possíveis componentes de uma experiência eudaimônica; e (3) identificar empiricamente os fatores constituintes da experiência turística eudaimônica. Para o alcance dos dois primeiros objetivos, realizou-se uma extensa revisão da literatura nos campos da psicologia positiva, psicologia existencialhumanista, psicologia do desenvolvimento (estudos sobre a formação da identidade), e turismo (estudos sobre experiência turística). Para o terceiro objetivo, um levantamento foi empreendido junto a pessoas que reconheceram ter passado por uma experiência de viagem que teve alguma influência para quem elas são no atual momento de suas vidas.

O artigo está dividido em 5 seções, incluindo esta introdução. A segunda seção expõe o referencial teórico empreendido para a consecução dos objetivos do estudo. A terceira seção explicita os procedimentos metodológicos utilizados no survey, enquanto a quarta seção traz os resultados desse levantamento e os discute. A quinta seção encerra o artigo com as principais conclusões e o alcance das descobertas, as limitações do estudo e proposições para estudos futuros.

\section{REFERENCIAL TEÓRICO}

\subsection{Psicologia positiva e o conceito de eudaimonia}

O estudo do desenvolvimento das capacidades humanas a partir da realização íntegra do eu interior tem sido alavancado com as pesquisas no campo denominado de psicologia positiva. No rastro da psicologia humanista, a psicologia positiva abandona o "modelo de doença" e segue na orientação da prevenção da doença mental, interessando-se pela descoberta do que funciona bem no ser humano comum, entendendo suas forças e virtudes e estudando o que é desenvolvido e aprimorado na pessoa (Seligman, 2002). A partir dessa perspectiva, a psicologia positiva tenta estabelecer um olhar mais apreciativo e uma postura mais 
aberta acerca das potencialidades, motivos e capacidades humanas (Sheldom e King, 2001). De forma geral, assim como na psicologia existencial-humanista, a psicologia positiva pode ser entendida como o estudo dos processos e condições que contribuem para o florescimento ou funcionamento ótimo das pessoas, grupos e instituições, por meio da inversão paradigmática do "pensamento patologizante", adotando a ênfase nas potencialidades e possibilitando uma compreensão mais holística do funcionamento humano (Gable e Haidt, 2005).

A psicologia positiva se baseia fortemente nos princípios da psicologia existencial-humanista, mas procura dar aos conceitos provenientes de sua predecessora e de ideias mais antigas da filosofia, como a de felicidade ou, bem viver, um caráter mais científico, tentando desenvolver constructos empiricamente verificáveis. Muitos conceitos e teorias que hoje são colocados no campo da psicologia positiva foram desenvolvidos antes de seu batismo no fim dos anos 90 e início da década de 2000, como a teoria da autodeterminação (Ryan e Deci, 2017, 2000), o desenvolvimento do constructo bem-estar subjetivo (Diener, 1984) e bem-estar psicológico (Ryff e Singer, 2008, 1998), a teoria da expressividade pessoal (Waterman, 2008, 1993), a teoria do fluxo (Csikszentmihalyi, 1990), e os conceitos de crescimento pessoal, autorrealização (Maslow, 1993) e funcionamento pleno (Rogers, 2009), provenientes da psicologia humanista. 0 conceito central que tem norteado os estudos no campo da psicologia positiva é exatamente o de eudaimonia.

Em Ética à Nicômaco, Aristóteles preconiza que a boa vida seria aquela vivida em consonância com o daimon (Waterman, 1993), sendo, portanto, eudaimonia o tipo de vida que se pensa melhor, ou mais valiosa, ou mais desejável (Waterman, 1990). Segundo Norton (1976), daimon seria um espírito que as pessoas recebem quando nascem. Contudo, o entendimento mais aceito de daimon é o significado de eu verdadeiro, o self ou o "[...] conjunto de características inatas com as quais cada pessoa nasce e deve descobrir dentro de si mesmo" (Schlegel, Hicks, e Christy, 2016, p. 205). Dessa forma, eudaimonia seria um estado alcançado a partir do esforço para se viver de acordo com o daimon, entendido como um ideal de excelência e perfeição que dá sentido e direção à vida (Waterman, 1993). Essa busca se dá por meio da realização das próprias capacidades e daquelas compartilhadas por todos os seres humanos (Waterman, 1993).

A descoberta do self, o eu verdadeiro, estaria sustentada por três princípios ou direcionadores primordiais do comportamento, segundo os autores da psicologia existencial-humanista: (1) a busca de crescimento pessoal, "[...] uma vontade ativa em relação à saúde, um impulso para o crescimento, ou para a realização das potencialidades humanas" (Maslow, 1993, p. 24); (2) a busca da autorrealização, o tornar-se si mesmo por meio da realização dos próprios talentos, potenciais e capacidades, da aceitação da própria natureza, e em direção à integração e unidade interior (Maslow, s. d.); e (3) o princípio do funcionamento pleno (Rogers, 2009), que derivaria dos dois primeiros e levaria em conta o contexto de vida mais amplo do indivíduo. Segundo esse princípio, o indivíduo plenamente funcional está aberto às experiências proporcionadas pela vida, seja objetiva ou subjetivamente, o que traz consigo uma série de atitudes relacionadas, como tolerância à ambiguidade e a tendência de perceber eventos com neutralidade, sem distorcê-los defensivamente ou censurá-los da consciência (Kernis e Goldman, 2006).

O estado eudaimônico tem sido traduzido como o equivalente à felicidade, alcançada com a realização plena da verdadeira natureza humana, por meio do exercício de virtudes pessoais e potenciais em busca do bem supremo (Delle Fave, Brdar, Freire, Vella-Brodrick, e Wissing, 2011). Contudo, segundo Ryan e Martela (2016), o conceito de eudaimonia tem sido mal interpretado quando concebido unicamente como o equivalente à felicidade ou como uma experiência subjetiva que se assemelha ao prazer ou ao engajamento. Para os autores, eudaimonia deve ser entendida como uma modo de vida que prioriza a virtude e a plenitude, cujos ingredientes contribuem para a felicidade e a prosperidade. Nesse sentido, os autores propõem que um modo de vida eudaimônico é caracterizado por objetivos intrínsecos, autonomia, atenção plena e benevolência, fatores que podem levar à melhoria do bem-estar.

A conceptualização de Ryan e Martela (2016) se aproxima da chamada felicidade perfeccionista [perfectionist happiness], definida como sinônimo de eudaimonia (Sirgy e Uysal, 2016). Em contraste com a felicidade psicológica (hedonia) e a felicidade prudente (satisfação com a vida), a felicidade perfeccionista refere-se a uma vida que é boa em todos os aspectos, incluindo a vida moral (Sirgy e Uysal, 2016). 
No entanto, o termo eudaimonia tem sido melhor entendido como florescimento [flourishing] (Padilla-Walker e Nelson, 2017, Huppert e So, 2013, Seligman, 2011, Ryff e Keyes, 1995, Keyes e Haidt, 2003) e tem sido esse o enfoque dado pelos estudos no novel campo da psicologia positiva. Conceber o bem-estar a partir da ideia de eudaimonia (Huta, 2016, Waterman et al., 2010, Kashdan, Biswas-Diener, e King, 2008, Waterman, 2008, 1993, 1990; Ryan e Deci, 2001) em vez de apenas o "sentir-se bem hedônico" ou como a "satisfação com a vida" (Diener, 1984) tem permitido um entendimento mais completo acerca dos fatores psicológicos que facilitam o desenvolvimento das potencialidades inatas individuais, contribuem para a autorrealização e proporcionam o florescimento (Gallagher, Lopez, e Preacher, 2009).

Com base nessas conceituações, a experiência turística eudaimônica pode ser definida como o conjunto percebido de benefícios relacionados ao crescimento pessoal, à autorrealização, às percepções relacionadas à autodescoberta e à autoconsciência e ao desenvolvimento das próprias potencialidades, viabilizando o processo de realização do eu interior ou da autoidentidade, tudo isso proporcionado pelo engajamento em atividades pessoalmente expressivas e reflexões subjetivas decorrentes da experiência em um ambiente turístico.

\subsection{Experiência turística e transformações pessoais positivas}

Kirillova, Lehto e Cai (2017) afirmam que as experiências transformadoras são eventos especialmente extraordinários que não apenas desencadeiam respostas emocionais intensas, mas também conduzem à auto exploração, servem como veículo para mudanças intrapessoais profundas e proporcionam o funcionamento humano ótimo. Bestrom (2009) esclarece que, ao se colocar fora do domínio da familiaridade, em um mundo onde ele, o viajante/turista é o estrangeiro, o outro, uma perspectiva diferente Ihe é posta, levando-o a ter uma visão valiosa do significado da diferença e da identidade em nosso mundo. Reisinger (2013) define a transformação como uma mudança irreversível em relação ao crescimento pessoal por meio de um processo de ruptura fundamental com as práticas passadas ou atuais, requerendo novos conhecimentos. Kottler (2002) explica que, ao viajar e se expor à diversidade, a pessoas e lugares não familiares, o indivíduo pode ser levado a um processo de mudança de perspectiva, com impacto duradouro para a sua própria vida, mudando o curso do conhecimento, dos valores, das atitudes e do próprio comportamento.

Kottler $(2002,1998)$ afirma que, muitas vezes, em terras estrangeiras (que podem estar dentro do próprio país) a pessoa sofre uma mudança irrevogável e permanente como resultado do que encontrou e do que aprendeu. Segundo o autor, em geral, tais experiências de viagem resultam de seis possíveis situações que podem atuar de forma combinada: (1) a pessoa se vê obrigada a resolver problemas de maneira nova, uma vez que em lugares com culturas diferentes da sua, o indivíduo precisa atender suas necessidades de uma forma que não está acostumado a fazer; (2) quando a pessoa se encontra em um novo ambiente e se defronta com novos e diferentes estímulos; cenários diferentes, sons, cheiros e sensações tornam a pessoa hipersensivel ao seu ambiente; (3) quando a pessoa se vê perdida ou enfrenta adversidades, mas consegue sobreviver de uma maneira que a torna mais resiliente; muitas viagens transformadoras acontecem quando as estruturas da vida diária, como o horário e a rotina, se desmoronam, quando o indivíduo se sente "perdido" e desorientado; (4) quando a pessoa desenvolve novos relacionamentos ou aumenta os níveis de intimidade em um relacionamento atual; (5) quando a pessoa desenvolve uma perspectiva diferente sobre a vida, passando a enxergá-la através dos olhos de uma cultura diferente; e (6) quando as crenças centrais do indivíduo são abaladas até o ponto em que a pessoa é levada a grandes mudanças em seu retorno; as experiências de viagens em uma cultura diferente desafiam as crenças e a visão de mundo que se tem, muitas vezes exigindo que se examinem os próprios pressupostos mais apreciados sobre si mesmo e sobre o mundo.

Por meio de extensa revisão da literatura nos domínios da psicologia positiva, da psicologia humanistaexistencial, da psicologia do desenvolvimento, com os estudos sobre a formação da identidade, e do turismo, especificamente com as pesquisas que tratam das transformações pessoais proporcionadas por experiências turísticas, foi possivel sintetizar 15 dimensões potencialmente constituintes da experiência turística eudaimônica. 0 quadro 1 a seguir explicita cada uma dessas dimensões, trazendo suas respectivas definições e as principais fontes às quais estão fundamentadas. 
Quadro 1 - Dimensões teorizadas da Experiência Turística Eudaimônica

\begin{tabular}{|c|c|c|}
\hline Dimensão & Definição & Fonte \\
\hline $\begin{array}{l}\text { Significado e } \\
\text { Propósito na vida }\end{array}$ & $\begin{array}{l}\text { O sentido e o significado atribuído à na- } \\
\text { tureza do ser e da própria existência } \\
\text { (Steger, Frazier, Oisho e Kaler, 2006); } \\
\text { Objetivos e intenções que dão um sen- } \\
\text { tido de orientação e contribuem para } \\
\text { dar significado à vida. }\end{array}$ & $\begin{array}{l}\text { Kirillova, Lehto e Cai, 2017, Huta, 2016, } \\
\text { Frankl, 2016, Waterman et al., 2010, } \\
\text { Seligman, 2011, Ryff e Singer, 2008, } \\
\text { 2003, Steger et al., 2006, Huta e Ryan, } \\
\text { 2010, Ryan e Deci, 2001, Erikson, } \\
\text { 1972, Ryff, 1989, Jahoda, } 1958\end{array}$ \\
\hline $\begin{array}{l}\text { Autodesenvolvimento e } \\
\text { Crescimento pessoal }\end{array}$ & $\begin{array}{l}\text { Percepção de que, com o passar do } \\
\text { tempo, a pessoa se desenvolveu como } \\
\text { alguém com personalidade e caracterís- } \\
\text { ticas próprias e evoluiu como ser hu- } \\
\text { mano; desejo, vontade e disposição } \\
\text { para continuar se desenvolvendo com a } \\
\text { realização dos melhores potenciais e ca- } \\
\text { pacidades, aquisição de conhecimento } \\
\text { e habilidades, e a convicção de que se } \\
\text { está em um contínuo processo de aper- } \\
\text { feiçoamento; coragem no enfrenta- } \\
\text { mento e superação das adversidades e } \\
\text { provações da vida a partir da própria } \\
\text { força interior. }\end{array}$ & $\begin{array}{l}\text { Huta, 2016, Waterman et al., 2010, Ro- } \\
\text { gers, } 2009 \text {, Ryff e Singer, 2008, 1996, } \\
\text { Ryff, } 1989\end{array}$ \\
\hline $\begin{array}{l}\text { Autoconhecimento e Au- } \\
\text { toaceitação }\end{array}$ & $\begin{array}{l}\text { Disposição para conhecer a si próprio, } \\
\text { reconhecendo as características positi- } \\
\text { vas e negativas, com imparcialidade e } \\
\text { resignação; Consciência dos aspectos } \\
\text { positivos e negativos de si próprio, mas } \\
\text { com uma atitude positiva em relação a } \\
\text { eles, reconhecendo as próprias limita- } \\
\text { ções e orientando-se na direção da su- } \\
\text { peração das características que são } \\
\text { passíveis de modificação e que não se } \\
\text { mostraram eficazes no enfrentamento } \\
\text { dos desafios da vida (Ryff; Keyes, } 2008 \text {, } \\
\text { 1995). }\end{array}$ & $\begin{array}{l}\text { Schlegel, Hicks e Christy, 2016, Matteu- } \\
\text { cci e Filep, 2015, Waterman et al., } \\
\text { 2010, Rogers, 2009, Ryff e Singer, } \\
\text { 2008, 1996, Kernis e Goldman, 2006, } \\
\text { Waterman, 2007; 2004, } 1984\end{array}$ \\
\hline Autoexpressividade & $\begin{array}{l}\text { Envolvimento intenso em atividades que } \\
\text { fazem pleno uso das melhores habilida- } \\
\text { des e talentos e que são a exata tradu- } \\
\text { ção de quem a pessoa é; atividades pes- } \\
\text { soalmente significativas, que vêm acom- } \\
\text { panhadas de sentimentos de autorreali- } \\
\text { zação e experiência ótima que dão sen- } \\
\text { tido e direção à vida. }\end{array}$ & $\begin{array}{l}\text { Waterman et al., 2010, Waterman, } \\
2008,2004,1993,1992,1990\end{array}$ \\
\hline Pertencimento & $\begin{array}{l}\text { Senso de pertencimento a uma comuni- } \\
\text { dade ou grupo de pessoas com as quais } \\
\text { se compartilha uma mesma experiência } \\
\text { ou situação; relações desprovidas de } \\
\text { status provenientes de papéis sociais e } \\
\text { hierarquia; sentimento de igualdade e } \\
\text { "conexão". }\end{array}$ & $\begin{array}{l}\text { Kirillova, Lehto e Cai, 2017, Wang, } \\
\text { 1999, Arnould e Price, } 1993\end{array}$ \\
\hline $\begin{array}{l}\text { Intimidade e Relaciona- } \\
\text { mento }\end{array}$ & $\begin{array}{l}\text { Relação harmoniosa e confiante com } \\
\text { outras pessoas; sinceridade e abertura } \\
\text { junto a pessoas próximas e preocupa- } \\
\text { ção com o seu bem-estar e felicidade; } \\
\text { reciprocidade e empatia; dar e receber } \\
\text { amor, carinho, afeto, aconchego e apoio. }\end{array}$ & $\begin{array}{l}\text { Kirillova, Lehto e Cai, 2017, Ryff e Sin- } \\
\text { ger, 2008, 2003, 1996, Kernis e Gold- } \\
\text { man, 2006, Kottler, 2002, 1998, Wang, } \\
\text { 1999, Erikson, } 1972\end{array}$ \\
\hline
\end{tabular}


Quadro 1 - Dimensões teorizadas da Experiência Turística Eudaimônica

\begin{tabular}{|c|c|c|}
\hline Dimensão & Definição & Fonte \\
\hline $\begin{array}{l}\text { Autenticidade e Esponta- } \\
\text { neidade }\end{array}$ & $\begin{array}{l}\text { Ser quem verdadeiramente se é; agir de } \\
\text { acordo com o verdadeiro eu e em con- } \\
\text { formidade com os próprios valores, ne- } \\
\text { cessidades e convicções; apresentar-se } \\
\text { de forma que reflita a própria essência e } \\
\text { relacionar-se de maneira honesta e ver- } \\
\text { dadeira com as outras pessoas. }\end{array}$ & $\begin{array}{l}\text { Kirillova, Lehto e Cai, 2017, Canavan, } \\
\text { 2017, Kirillova, Lehto e Cai, 2016b, } \\
\text { Huta, 2016, Kirillova e Lehto, 2015, } \\
\text { Xue, Manuel-Navarrete e Buzinde, } \\
\text { 2014, Brown, 2013, Rickly-Boyd, 2012, } \\
\text { Kim e Jamal, 2007, Seligman, 2011, } \\
\text { Wood, Linley, Maltby, Baliousis e Joseph, } \\
\text { 2008, Kernis e Goldman, 2006, Peter- } \\
\text { son e Seligman, 2004, Wang, } 1999\end{array}$ \\
\hline Autonomia & $\begin{array}{l}\text { Capacidade de pensar e agir de forma } \\
\text { independente, de ter ideias e convic- } \\
\text { ções próprias, mesmo que vão contra o } \\
\text { "dogma" aceito ou a sabedoria conven- } \\
\text { cional (Hidalgo, Bravo, Martínez, Pretel, } \\
\text { Postigo e Rabadán, 2010). }\end{array}$ & $\begin{array}{l}\text { Ryan e Deci, 2017, 2000, Ryan, Deci, } \\
\text { Grolnick e La Guardia, 2006, Ryff e Sin- } \\
\text { ger, 2008, 2003, Erikson, 1972, Ryff, } \\
\text { 1989, Jahoda, } 1958\end{array}$ \\
\hline Competência & $\begin{array}{l}\text { Sentimento de que se é capaz de reali- } \\
\text { zar alguma atividade ou empreendi- } \\
\text { mento. }\end{array}$ & $\begin{array}{l}\text { Ryan e Deci, 2017, Ryan et al., 2006, } \\
\text { Peterson e Seligman, 2004, Erikson, } \\
1972\end{array}$ \\
\hline Excelência & $\begin{array}{l}\text { Esforço extra para alcançar padrões ele- } \\
\text { vados de desempenho, comportamento } \\
\text { e ética. }\end{array}$ & $\begin{array}{l}\text { Huta, 2016, Huta e Ryan, 2010, Water- } \\
\text { man et al., 2010, Peterson e Seligman, } \\
2004\end{array}$ \\
\hline Empatia & $\begin{array}{l}\text { Capacidade de se colocar no lugar de } \\
\text { outra pessoa, tentando entender sua } \\
\text { perspectiva da situação. }\end{array}$ & $\begin{array}{l}\text { Bestrom, 2009, Ryff e Singer, 2008, } \\
\text { 2003, 1996, Kottler, 2002, 1998, Ryff, } \\
1989\end{array}$ \\
\hline Tolerância & $\begin{array}{l}\text { Capacidade de aceitar as diferenças; sa- } \\
\text { ber conviver com pessoas que possuem } \\
\text { ideias, crenças, modos de vida e valores } \\
\text { diferentes dos da própria pessoa. }\end{array}$ & Bestrom, 2009, Kottler, 2002, 1998 \\
\hline Perspectiva ampliada & $\begin{array}{l}\text { Senso desenvolvido de percepção que } \\
\text { considera diferentes pontos de vista e } \\
\text { entendimentos sobre um mesmo fenô- } \\
\text { meno, proporcionando uma compreen- } \\
\text { são mais lúcida acerca dos fatos da } \\
\text { vida. }\end{array}$ & $\begin{array}{l}\text { Bestrom, 2009, Peterson e Seligman, } \\
\text { 2004, Roberson, 1999, Kottler, 2002, } \\
\text { 1998, Maslow, } 1959\end{array}$ \\
\hline Benevolência & $\begin{array}{l}\text { Capacidade de oferecer ajuda, cuidado } \\
\text { e generosidade de forma espontânea e } \\
\text { desinteressada; ter compaixão e amor } \\
\text { altruísta. }\end{array}$ & $\begin{array}{l}\text { Ryan e Martela, 2016, Seligman, } 2011 \text {, } \\
\text { Peterson e Seligman, } 2004\end{array}$ \\
\hline Abertura ao novo & $\begin{array}{l}\text { Disposição para novas experiências; } \\
\text { mente aberta a novas ideias, modos de } \\
\text { vida e possibilidades. }\end{array}$ & $\begin{array}{l}\text { Seligman, 2011, Rogers, 2009, Ryff e } \\
\text { Singer, 2008, 1996, Peterson e Selig- } \\
\text { man, } 2004\end{array}$ \\
\hline
\end{tabular}

Fonte: Elaborado pelos autores a partir da literatura consultada

\section{MATERIAL E MÉTODOS}

\subsection{Escalas de medida}

A fim de acessar cada uma das dimensões teorizadas da experiência turística eudaimônica (ETE) foram desenvolvidos 96 itens a partir da revisão da literatura. Os itens foram elaborados de modo a refletirem algum aspecto da dimensão que representavam, de acordo com a definição da dimensão. Os indicadores foram mensurados segundo uma escala de 10 pontos ( 1 = Nada a ver comigo / $10=$ Tudo a ver comigo).

\subsection{Coleta e preparação dos dados}

No período compreendido entre 25/05/2018 e 15/09/2018, 578 questionários válidos foram coletados. Desse total, 411 foram questionários físicos e 167 respostas provenientes de sua versão digital, hospedada na plataforma GoogleDocs ${ }^{\circledR}$ e disponibilizada via email e redes sociais (Facebook ${ }^{\circledR}$ e WhatsApp $^{\circledR}$ ). 
A abordagem do questionário físico se deu com a visita prévia a Instituições de Ensino Superior sediadas na capital do Estado de Alagoas (local de residência do primeiro pesquisador) e a devida explicitação dos objetivos da investigação a dirigentes e coordenadores de curso, que autorizaram a aplicação do questionário junto aos alunos em horário de aula, com a presença do respectivo professor, também informado acerca dos objetivos da pesquisa.

Aqueles que aderiam livremente ao estudo eram solicitados a lembrar da experiência de viagem que mais contribuiu para quem eles eram no momento atual de suas vidas. Com base nas memórias dessa experiência de viagem, os participantes responderam o inquérito. 0 tempo mínimo de resposta foi de 25 minutos e o tempo máximo de cerca de 45 minutos. Os dados coletados por questionário físico foram tabulados em software estatístico (SPSS ${ }^{\circledR}$ ). Os dados provenientes das respostas ao questionário on-line, registrados automaticamente na plataforma GoogleDocs ${ }^{\circledR}$, foram transferidos para a mesma base de dados no SPSS ${ }^{\circledR}$.

Após a avaliação inicial, os dados foram submetidos a procedimentos de verificação e tratamento de dados ausentes, outliers e normalidade, quando então passaram a estar aptos à análise multivariada. A amostra final consistiu de 569 sujeitos, quantidade suficiente para a execução da análise fatorial exploratória, segundo a regra de pelo menos 5 observações para cada variável analisada (Hair, Black, Babin, e Anderson, 2014).

\subsection{Análise dos dados}

A fim de reduzir o número total de itens e de verificar a estrutura dimensional latente aos dados empíricos, procedeu-se a análise fatorial exploratória por meio do método das componentes principais com rotação oblíqua [oblimin rotation], preferível quando se tem constructos significativamente fundamentados em teoria (Hair et al., 2014).

\section{RESULTADOS E DISCUSSÃO}

\subsection{Perfil sociodemográfico da amostra}

No que se refere ao gênero, houve pequena predominância de pessoas do sexo masculino na amostra, representando $53,6 \%$ das observações válidas. Já no que diz respeito ao status marital, a grande maioria era de solteiros, representando $61,6 \%$ do total válido de observações. No que concerne à educação formal, quase metade dos sujeitos da amostra possuía ensino médio, representando $48,4 \%$ das observações válidas, enquanto $24,9 \%$ possuía o nível superior.

A idade dos sujeitos variou de 18 a 74 anos, com média de 29,22 anos. A grande concentração se deu entre os 18 e 35 anos. 0 valor mais comum foi 19 anos, enquanto o valor central foi 26 anos. A tabela 1 a seguir sintetiza o perfil sociodemográfico da amostra.

Tabela 1 - Perfil sociodemográfico da amostra

\begin{tabular}{|c|c|c|c|c|c|c|c|c|}
\hline \multirow{2}{*}{ Gênero } & & & \multicolumn{3}{|l|}{ Masculino } & \multicolumn{3}{|l|}{ Feminino } \\
\hline & & & $53,6 \%$ & & & $46,4 \%$ & & \\
\hline \multirow{2}{*}{$\begin{array}{l}\text { Status } \\
\text { marital }\end{array}$} & & Solteiro & Casado & $\begin{array}{l}\text { Separado / } \\
\text { Divorciado }\end{array}$ & União estável & Viúvo & & \\
\hline & & $61,6 \%$ & $25,7 \%$ & $6,7 \%$ & $5,1 \%$ & $0,9 \%$ & & \\
\hline \multirow{2}{*}{$\begin{array}{l}\text { Educação } \\
\text { formal }\end{array}$} & & Fundamental & Médio & Superior & Espec./MBA & Mestrado & Doutorado & \\
\hline & & $0,9 \%$ & $48,4 \%$ & $24,9 \%$ & $11,1 \%$ & $11,0 \%$ & $3,7 \%$ & \\
\hline \multirow[t]{2}{*}{ Idade } & Média & Mediana & Moda & $\begin{array}{l}\text { Desvio pa- } \\
\text { drão }\end{array}$ & Assimetria & Curtose & Mínimo & Máximo \\
\hline & 29,22 & 26 & 19 & 11,153 & 1,368 & 1,534 & 18 & 74 \\
\hline
\end{tabular}

Fonte: Elaboração dos autores a partir da saída do SPSS ${ }^{\circledR}$ com os dados da pesquisa (2018)

\subsection{Análise fatorial exploratória}

Os 96 itens desenvolvidos para representarem as 15 dimensões teorizadas como possíveis componentes do constructo experiência turística eudaimônica (ETE), a partir de sua definição teórica, foram submetidos à 
análise das componentes principais com rotação oblíqua. 0 teste Kaiser-Meyer-Olkin de adequação da amostra $(\mathrm{KMO}=0,956)$ e o teste de esfericidade de Bartlett $\left(X^{2}=15409,028 ; 861\right.$ g.l.; $\left.p<0,001\right)$ indicaram a viabilidade da análise fatorial. Itens com comunalidades inferiores a 0,400 foram excluídos, bem como aqueles com cargas fatoriais menores que 0,600 ou carregados em mais de um fator. Como consequência, 55 itens foram eliminados. Seis fatores foram extraídos na solução final, explicando 62,636\% da variância total. A consistência interna de cada fator foi elevada, com o $\alpha$ de Cronbach $(0,797 \leq \alpha \leq 0,932)$ sempre acima dos limites mínimos aceitáveis. A tabela 2 a seguir sintetiza os resultados da solução fatorial.

Tabela 2 - Solução fatorial da Experiência Turística Eudaimônica - ETE

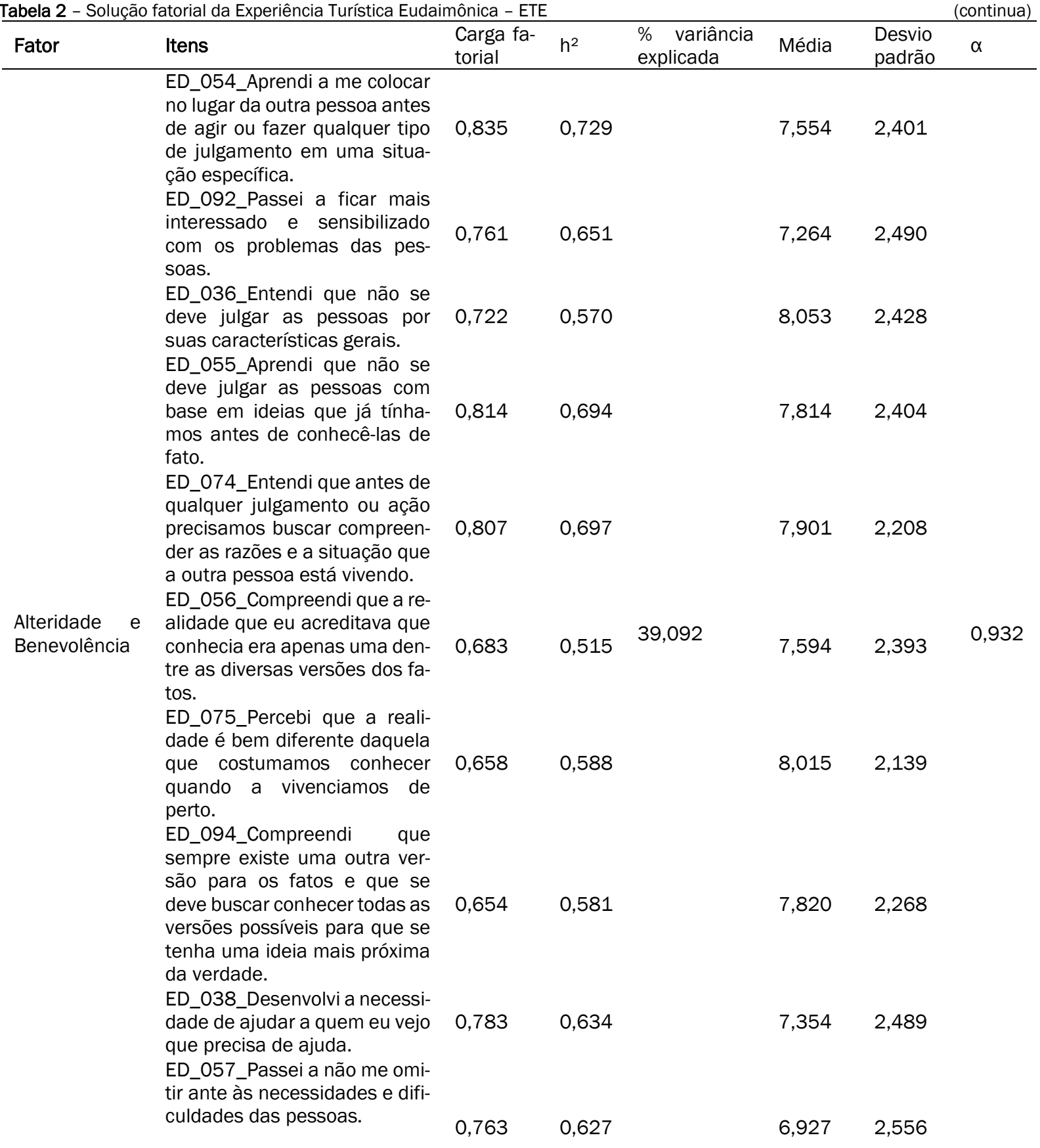


Tabela 2 - Solução fatorial da Experiência Turística Eudaimônica - ETE

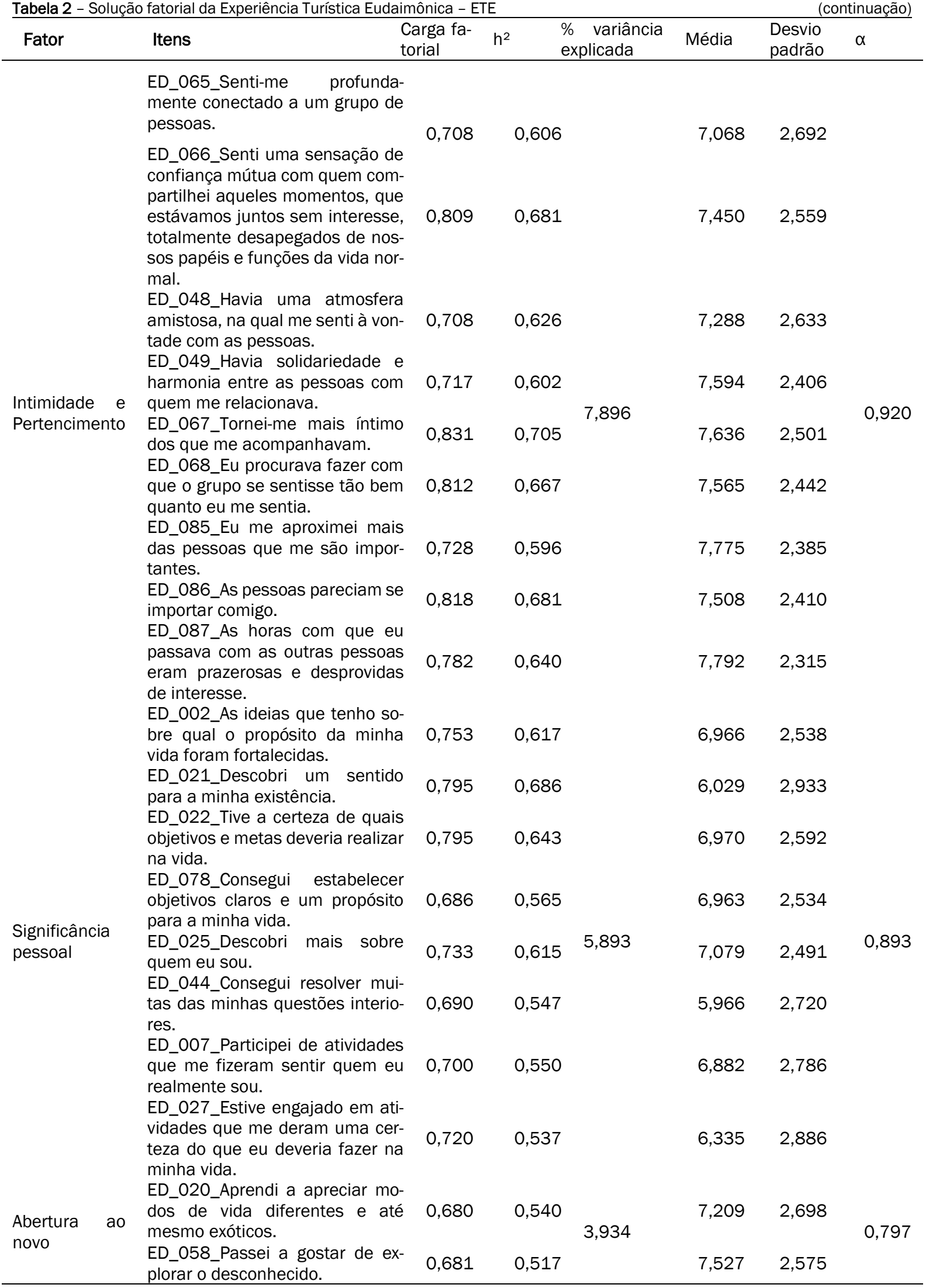


Tabela 2 - Solução fatorial da Experiência Turística Eudaimônica - ETE

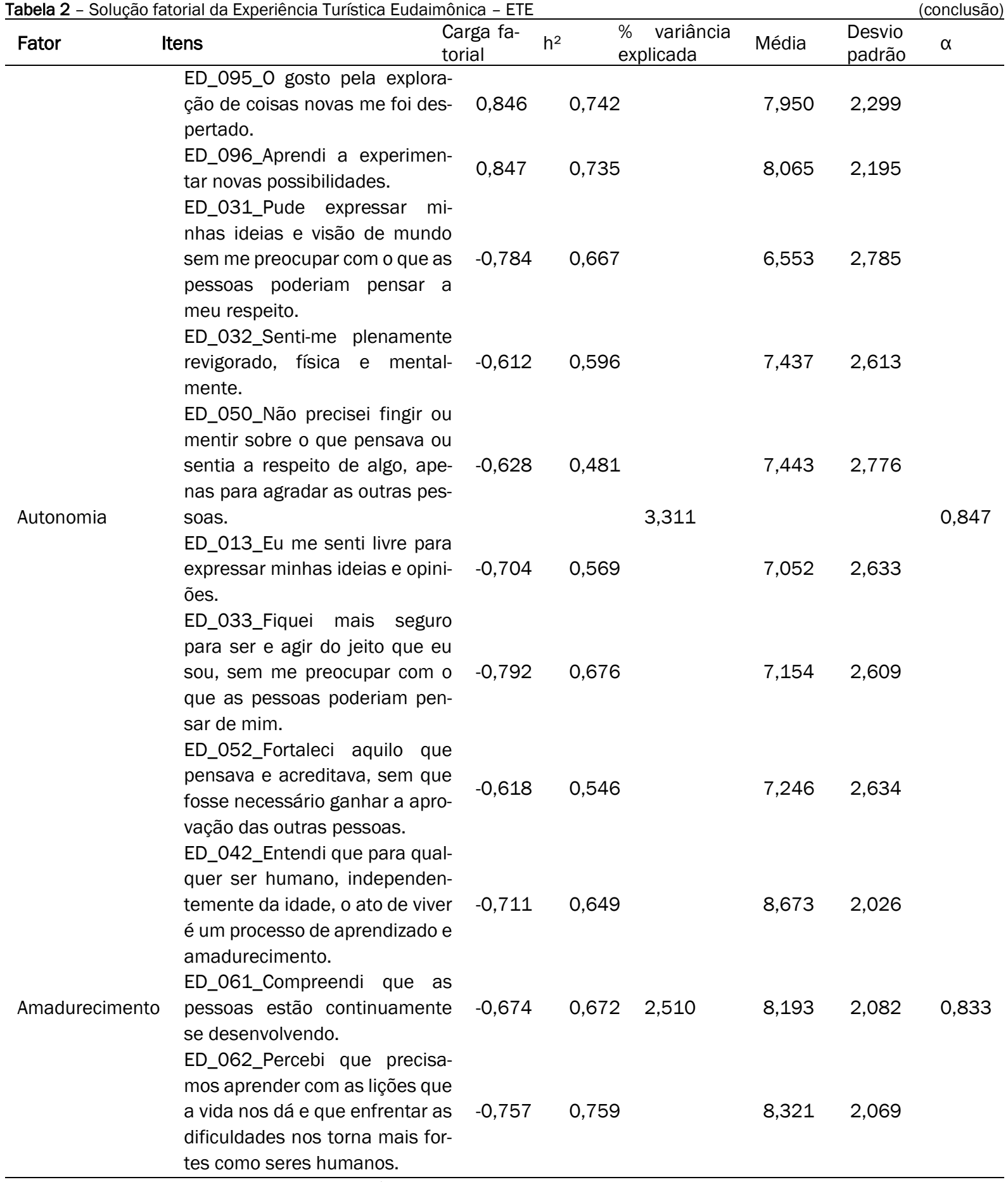

Fonte: Elaboração dos autores a partir da saída do SPSS ${ }^{\circledR}$ com os dados da pesquisa (2018)

\subsubsection{Interpretação dos fatores}

O primeiro fator foi formado por 11 itens que representavam originalmente as dimensões Empatia (ED_054; ED_092), Tolerância (ED_036; ED_055; ED_074), Perspectiva ampliada (ED_056; ED_075; ED_094) e Benevolência (ED_038; ED_057; ED_076), explicando 39,092\% da variância total. A consistência interna do fator foi bastante alta $(\alpha=0,932)$. Os itens fazem alusão a um processo de tomada de consciência em relação ao outro, que vai da percepção de realidades diferentes da do próprio indivíduo, passando pela empatia, pela aceitação de outros modos de vida e compreensão das diferenças, culminando com uma atitude altruísta e benevolente. 
Empatia significa a capacidade de se colocar no lugar de outra pessoa, tentando entender sua perspectiva da situação (Bestrom, 2009, Ryff e Singer, 2008, 2003, 1996, Kottler, 2002, 1998). A Tolerância corresponde à capacidade de aceitar as diferenças; saber conviver com pessoas que possuem ideias, crenças, modos de vida e valores diferentes dos da própria pessoa (Bestrom, 2009, Kottler, 2002, 1998). Já a Perspectiva ampliada representa o senso desenvolvido de percepção que considera diferentes pontos de vista e entendimentos sobre um mesmo fenômeno, proporcionando uma compreensão mais lúcida acerca dos fatos da vida (Bestrom, 2009, Peterson e Seligman, 2004, Roberson, 1999, Kottler, 2002, 1998, Maslow, 1959). Benevolência corresponde à capacidade de oferecer ajuda, cuidado e generosidade de forma espontânea e desinteressada; ter compaixão e amor altruísta (Ryan e Martela, 2016, Seligman, 2011, Peterson e Seligman, 2004).

A fim de refletir o processo de consciência de outras possiveis realidades e o reconhecimento do outro, o que inclui os itens representativos da Empatia, da Tolerância e da Perspectiva ampliada, optou-se por nomear esse conjunto de Alteridade. No entanto, esse nome desconsidera a característica do altruísmo que é destacada pelos itens representativos da dimensão original Benevolência. Assim, com o objetivo de preservar os conceitos das dimensões originais, o nome escolhido para o fator foi Alteridade e Benevolência, passando a contemplar todas as transformações pessoais sugeridas pelos indicadores.

O segundo fator foi formado por 9 itens provenientes das dimensões originais Pertencimento (ED_065; ED_066) e Intimidade/Relacionamento (ED_048; ED_049; ED_067; ED_068; ED_085; ED_086; ED_87), representando o aspecto social da experiência turística. Os nomes das dimensões originais foram mantidos para designar o fator: Intimidade e Pertencimento. 0 fator explicou $7,896 \%$ da variância total e sua consistência interna foi elevada $(\alpha=0,920)$.

Intimidade e Pertencimento diz respeito à relação harmoniosa e confiante com outras pessoas. Representa a sinceridade e a abertura junto a pessoas próximas e preocupação com o seu bem-estar e felicidade; também inclui a reciprocidade e a empatia. Corresponde a dar e receber amor, carinho, afeto, aconchego e apoio (Ryff e Singer, 2008, Kernis e Goldman, 2006, Wang, 1999, Kottler, 2002, 1998, Ryff, 1989, Erikson, 1972). Relacionamento é uma necessidade humana básica e praticamente todas as abordagens teóricas e clínicas acerca do desenvolvimento humano inclui o domínio das relações interpessoais como crucial para uma vida bem vivida (Ryff e Singer, 2008).

Ryan e Deci (2017) defendem que a necessidade de relacionamento se refere ao sentimento de sentir-se socialmente conectado, e que esse sentimento é ainda mais forte quando as pessoas se sentem cuidadas por outras. Contudo, os autores salientam que a necessidade de relacionamento, ou, como eles também se referem, de pertencimento [belonging], também inclui o sentir-se importante e necessário para outras pessoas. Nesse sentido, o pertencimento diz respeito ao experimentar-se a si mesmo como contribuindo (no sentido de "doar-se") para a vida de outras pessoas. Ryan e Deci (2017) também incluem aqui o aspecto mais amplo do relacionamento, ligado à integração a organizações e grupos sociais, quando sentimentos de pertencimento e benevolência se fariam presentes.

A conexão significativa com outras pessoas tem sido relatada na literatura do turismo e do lazer como um importante fator de episódios de transformação pessoal positiva e promotora do bem-estar. Kirillova, Lehto e Cai (2017) identificaram dois tipos de conexão significativa com outras pessoas em seu estudo com indivíduos que relataram episódios de transformação pessoal em suas respectivas viagens: (1) as que, em condições de liminalidade, evocavam um senso de comunidade, reproduzindo o conceito de communitas (Turner, 2013), e (2) as que resultavam de encontros com membros da comunidade local. Além disso, para os participantes do estudo que viajaram na companhia de amigos ou familiares, os autores verificaram que a relação com essas pessoas passou a ser mais forte, contribuindo para dar mais significado à viagem.

No estudo de Matteucci e Filep (2015) com turistas que afirmaram vivenciar uma experiência espiritual na presença e participação do flamenco, uma dança e herança intangivel da Espanha na região da Andaluzia, constatou-se que tanto o ambiente físico quanto as interações entre os participantes podiam desencadear experiências significativas. Citando Salsman, Brown, Brechting e Carlson (2005), Matteucci (2013) conclui que a "A contribuição das interações sociais positivas para experiências espirituais é consistente com pesquisas que ressaltam a relação entre espiritualidade e ajustamento psicológico por meio de fatores como o apoio social percebido" (Matteucci, 2013, p. 121). 
No mesmo estudo, Matteucci e Filep (2015) destacam a experiência de communitas vivenciada pelos turistas, a fim de explicar a conexão que os participantes afirmavam sentir entre si. Citando Turner (2013), os autores reproduzem a definição do fenômeno: "uma mistura de "humildade e sacralidade, de homogeneidade e companheirismo' que emana da experiência positiva de turismo em condições liminais" (Matteucci e Filep, 2015, p. 7). Os autores afirmam que, como resultado das interações sociais, verificou-se o sentimento de amizade e o estabelecimento de laços especiais com artistas e colegas de flamenco, contribuindo para um ambiente positivo.

Em estudo já clássico, Arnould e Price (1993) verificaram o fenômeno communitas entre os participantes da atividade de rafting. Os autores observaram um sentimento evolutivo de comunhão com amigos, familiares e pessoas estranhas. Segundo Arnould e Price (1993), a communitas surge de maneira sutil ao longo do tempo, com a emergência e intensificação dos "sentimentos de lealdade, de pertencimento, de devoção do grupo a um objetivo transcendente [...] facilitados pela proximidade forçada e pelos desfiladeiros estreitos, pequenas áreas de acampamento, barcos e trabalho de equipe associados à própria atividade de rafting" (Arnould e Price, 1993, p. 34).

Saunders, Laing e Weiler (2013) investigaram praticantes de caminhadas de longa distância e verificaram como os benefícios sociais dessa atividade podem ser transformadores. Os pesquisadores observaram que, ao conhecerem outras pessoas que pensam da mesma forma, alguns participantes entravam em um novo mundo social, participando de outras caminhadas com o mesmo grupo. As conclusões dos estudiosos revelaram que "as relações interpessoais, bem como a consciência das necessidades de outras pessoas, levavam a resultados pessoais de crescimento para os praticantes [...]" (Filep e Pearce, 2013, p. 225).

Enfim, existem fartas evidências da presença de uma dimensão que reflete o aspecto social da experiência turística e os processos eudaimônicos a ela relacionados, especialmente no que diz respeito ao sentimento de conexão e pertencimento, uma necessidade humana fundamental. 0 sentimento de afiliação ou o senso de relacionamento social, parece consistir em um fundamental promotor do bem-estar (Newman, Tay, e Diener, 2014, Alexander e Bakir, 2013) e do desenvolvimento do self.

O terceiro fator foi formado por itens originários das dimensões Significado e Propósito na vida (ED_002; ED_021; ED_022; ED_078), Autoconhecimento e Autoaceitação (ED_025; ED_044) e Autoexpressividade (ED_007; ED_027), explicando 5,893\% da variância total e com consistência interna elevada $(\alpha=0,893)$.

O Significado e propósito na vida diz respeito ao sentido atribuído à natureza do ser e da própria existência (Steger et al., 2006), e corresponde aos objetivos e intenções que dão um sentido de orientação e contribuem para dar significado à vida (Seligman, 2011, Waterman et al., 2010, Ryff e Singer, 2008, Deci, 2001, Erikson, 1972, Jahoda, 1958). Para Ryff e Singer (2003), o propósito de vida corresponde à capacidade de se encontrar um significado e uma direção nas próprias experiências e de se propor e definir metas para a própria vida. Segundo Waterman et al. (2010), para se alcançar o estado de eudaimonia não basta identificar e reconhecer os melhores talentos e habilidades, mas, além disso, decidir para onde direcionar os objetivos de vida relacionados a esses talentos e habilidades. Nesse sentido, os indivíduos precisam encontrar maneiras de usar suas habilidades e talentos na busca de objetivos pessoalmente significativos (Waterman et al., 2010).

A dimensão Autoexpressividade reflete um aspecto fundamental na experiência eudaimônica (Waterman et al., 2010, Waterman, Schwartz, e Conti, 2008, Waterman, 2004), referindo-se ao engajamento em atividades que demandam o melhor uso das próprias potencialidades e capacidades e que são pessoalmente significativas.

A dimensão Autoconhecimento e Autoaceitação representa a disposição para conhecer a si próprio, reconhecendo as características positivas e negativas, com imparcialidade e resignação, orientando-se na direção da superação das características que são passíveis de modificação e que não se mostraram eficazes no enfrentamento dos desafios da vida (Hidalgo et al., 2010, Ryff e Keyes, 2008, 1995, Erikson, 1972). Conforme atestam Waterman et al. (2010), a ética eudaimônica convida cada pessoa a reconhecer e a viver de acordo com o seu daimon, ou seja, esforçar-se para realizar-se a si mesmo. Segundo essa filosofia, o conhecer-se a si mesmo precede o esforçar-se para realizar-se a si mesmo (Waterman et al., 2010). 
Significância pessoal [personal meaningfulness] foi o nome inicialmente dado por Waterman $(2004,1990)$ para um aspecto negligenciado nas pesquisas sobre o desenvolvimento da identidade que se orientavam pelo paradigma do status de identidade de James Marcia (1966). Após analisar milhares de entrevistas que acessavam o status de identidade, Waterman identificou uma dimensão até então não registrada na literatura sobre a formação da identidade. Essa nova dimensão se somava às duas dimensões - exploração e comprometimento - fundamentais para a classificação do status de identidade. Nas palavras de Waterman (2004, p. 210):

Ao ouvir as entrevistas, particularmente com indivíduos classificados no status de realização em vários domínios, a distinção ficou clara em alguns entrevistados para os quais os compromissos de identidade assumidos diziam respeito a escolhas pessoalmente expressivas e intrinsecamente motivadas. Em contrapartida, para os outros entrevistados, os compromissos assumidos eram principalmente escolhas instrumentais, extrinsecamente motivadas, por meio das quais poderiam trilhar seu caminho no mundo com relativo sucesso. Em outras palavras, embora esse grupo instrumental, após a consideração de alternativas, tivesse encontrado algo para fazer, os entrevistados mais expressivos haviam encontrado alguém para ser. [...]

A essa dimensão - significância pessoal - Waterman (1990) chamou de expressividade pessoal e a igualou ao conceito de eudaimonia. Dessa forma, a fim de representar todos os itens carregados no fator e as três dimensões originais correspondentes, além de se buscar evitar a ocorrência de tautologia, ao chamar uma componente do constructo teorizado por seu próprio nome [eudaimonia], o nome escolhido para o fator foi Significância pessoal.

O quarto fator foi inteiramente composto pelos itens da dimensão Abertura ao novo (ED_020; ED_058; ED_095; ED_096), sendo mantido o nome da dimensão. 0 fator explicou 3,943\% da variância total dos dados e seus quatro itens apresentaram boa consistência interna $(\alpha=0,797)$. Abertura ao novo corresponde à disposição para novas experiências; mente aberta a novas ideias, modos de vida e possibilidades (Seligman, 2011, Rogers, 2009, Ryff e Singer, 2008, 2003, Peterson e Seligman, 2004).

Abertura ao novo é uma características das pessoas plenamente funcionais (Rogers, 2009), que vivem o momento em sua plenitude, são flexíveis e experimentam a si próprios de forma fluida, não estática e rígida, além de serem autoconfiantes, guiando-se sem receio por suas intuições, uma vez que confiam em suas experiências subjetivas (Kernis e Goldman, 2006). Uma característica marcante a essas atitudes é a de como o indivíduo experimenta a liberdade e, por sua vez, como encara as experiências (Kernis e Goldman, 2006). Por exemplo, mesmo que o meio ambiente seja imobilizador, para o indivíduo ainda haverá a escolha de como responder e sentir sobre essa limitação (Kernis e Goldman, 2006).

0 quinto fator foi formado igualmente por itens originários das dimensões Autenticidade e Espontaneidade (ED_031; ED_032; ED_050; ED_078) e Autonomia (ED_013; ED_033; ED_52), explicando 3,311\% da variância dos dados. A consistência interna do fator foi alta $(\alpha=0,847)$. Com exceção do item ED_032 [Sentime plenamente revigorado, física e mentalmente], todos os demais fazem alusão à idependência de pensamento e opinião, características mais definidoras da Autonomia, razão pela qual o fator foi assim nomeado.

Autonomia diz respeito à capacidade de pensar e agir de forma independente, de ter ideias e convicções próprias, mesmo que vão contra o "dogma" aceito ou a sabedoria convencional (Hidalgo et al., 2010). Para Ryan e Deci (2017), o que caracteriza a autonomia são os comportamentos autoendossados da pessoa, congruentes com seus interesses e valores autênticos. Rogers (2009) afirma que as pessoas que funcionam de forma plena possuem o locus interno de avaliação, guiando-se apenas por meio de seus próprios padrões pessoais, não necessitando da aprovação de terceiros para tomar decisões e agir. Ademais, como resultado da autoconfiança e da sua atitude de flexibilidade e liberdade, o indivíduo plenamente funcional é criativo em sua abordagem de viver, recusando-se a recuar para modos de comportamento que se tornam desnecessariamente restritivos (Kernis e Goldman, 2006).

O sexto fator foi composto integralmente pelos itens da dimensão original Autodesenvolvimento e Crescimento pessoal (ED_042; ED_061; ED_095; ED_062), mas seus itens captaram o aspecto do amadurecimento como pessoa, refletido na compreensão acerca do desenvolvimento de todos os indivíduos, no entendimento de que as pessoas aprendem ao longo de toda a vida e na resignação no próprio ato de viver. Tais acepções remetem a uma postura mais resoluta em relação à vida, característica de 
pessoas mais amadurecidas. A fim de traduzir mais precisamente o conteúdo dos itens, e levando em conta que os itens não abrangem todos os aspectos relacionados à dimensão Autodesenvolvimento e Crescimento pessoal (embora ela esteja parcialmente contemplada), optou-se por nomear o fator de Amadurecimento. 0 fator explicou a menor quantidade de variação dos dados (2,510\%), mas sua consistência interna foi elevada $(\alpha=0,833)$, apesar do número reduzido de itens.

A partir da análise e interpretação dos dados, percebe-se que, com exceção do elemento emoções positivas, que enfatiza mais o aspecto hedônico (Sirgy e Uysal, 2016, Seligman, 2011), as dimensões da experiência eudaimônica captam elementos da estrutura PERMA relacionada ao florescimento humano (Seligman, 2011), mas enfatizando aspectos da autodescoberta e da construção no processo da formação da autoidentidade, especialmente as dimensões Intimidade e Relacionamento, Significância pessoal, Abertura ao novo, Autonomia e Amadurecimento, de forma condizente com o significado de eudaimonia e compatível com os estudos no campo do turismo que apontam para transformações pessoais positivas e a evolução do self em ambientes sob condições liminais.

Assim, com forte sustentação teórica, os resultados empíricos permitem conceber uma estrutura multidimensional para o constructo experiência turística eudaimônica, mais consistente com a complexidade desse tipo de experiência. A figura 1 a seguir ilustra essa abstração.

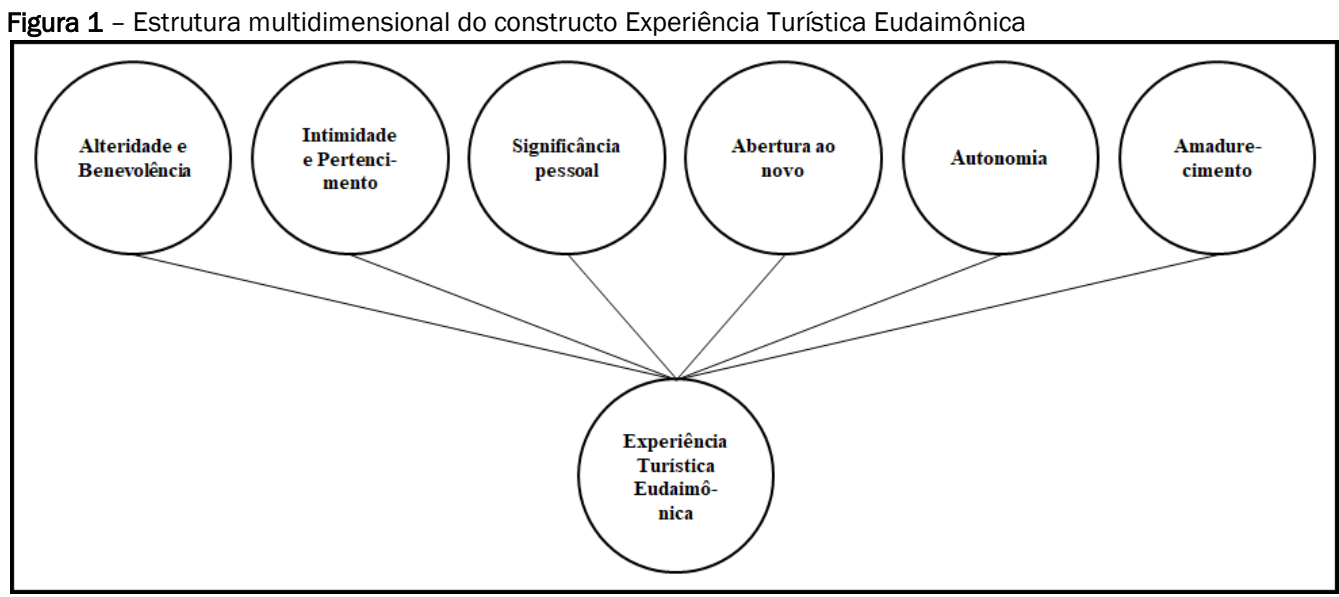

Fonte: Elaboração dos autores (2018)

\section{CONSIDERAÇÕES FINAIS}

O estudo oferece contribuições importantes para o campo do comportamento do turista e para o entendimento das experiências mais profundas vivenciadas em ambientes de turismo. 0 estudo assume que grande parte da experiência turística acontece durante as interações da pessoa com o ambiente, com outras pessoas, com a história e a cultura locais e que, nesse processo, o self é ampliado, expandido, desafiado, renovado e reforçado (Wearing, 2001), tornando a experiência um processo contínuo, que se estende para além da visita em si (Wearing e McGehee, 2013).

A pesquisa se fundamentou nos princípios filosóficos do conceito de eudaimonia, bem como em suas definições mais operacionais, desenvolvidas pelas mais recentes contribuições do campo da psicologia positiva e dos estudos sobre o bem-estar. As dimensões verificadas no levantamento empírico estão fortemente baseadas na teoria sobre eudaimonia, trazendo alguma luz para se entender um fenômeno crescentemente estudado, mas ainda carente de conceituações estruturadas e respaldo teórico-empírico no campo do turismo. 0 estudo enfatiza a descoberta e a construção da identidade como sendo o principal direcionador da experiência eudaimônica, fundamento que tem sido negligenciado na literatura do turismo.

A concepção do constructo como sendo multidimensional ajuda a pavimentar o caminho para que pesquisas futuras aprofundem o conceito e o refinem. Com esse objetivo, o estudo disponibiliza um instrumento 
testado para a mensuração/avaliação de transformações pessoais positivas, percebidas por pessoas em espaços turísticos.

Contudo, algumas limitações do estudo precisam ser evidenciadas a fim de orientar estudos futuros que possam ampliar o alcance de validação das descobertas. A primeira limitação diz respeito à amostra do levantamento, formada em sua grande maioria por estudantes universitários e não por turistas de fato. Ainda que se assuma que as experiências de viagens mais significativas para os indivíduos perdurem em sua memória, estudos futuros deveriam explorar a avaliação da experiência eudaimônica in situ. Embora menos viável, sugerem-se também estudos longitudinais, acompanhando as percepções de grupos de turistas ao longo do tempo.

Uma segunda limitação diz respeito a ausência de validação confirmatória das dimensões extraídas na análise fatorial exploratória. A fim de garantir uma estrutura dimensional estável para o constructo, pesquisas que façam uso da análise fatorial confirmatória por meio de modelagem de equações estruturais podem proporcionar validade mais robusta para o constructo, atestando sua validade preditiva e nomológica.

\section{REFERÊNCIAS}

Alexander, Z., \& Bakir, A. (2013). The development of self through volunteer tourism. In Filep, S., \& Pearce, P. L. (Eds.). Tourist experience and fulfilment; Insights from positive psychology. New York: Routledge. 147-164.

Andrews, H. (2009). Tourism as a moment of being. Suomen Antropologi, 34(2), 5-21.

Arnould, E. J., \& Price, L. L. (1993). River Magic: Extraordinary experience and the extended service encounter. Journal of Consumer Research, 20, 24-45. https://doi.org/10.1086/209331

Bestrom, E. (2009). Moving beyond borders: the creation of nomadic space through travel. Intersections, 10(1), 199-217.

Brown, L. (2013). Tourism: A catalyst for existential authenticity. Annals of Tourism Research, 40, 176-190. https://doi.org/10.1016/i.annals.2012.08.004

Canavan, B. (2017). An existentialist exploration of tourism sustainability: Backpackers fleeing and finding themselves. Journal of Sustainable Tourism, 26(4), 551-566. https://doi.org/10.1080/09669582.2017.1361430

Coghlan, A., \& Weiler, B. (2015). Examining transformative processes in volunteer tourism. Current Issues in Tourism, 21(5), 567-582. https://doi.org/10.1080/13683500.2015.1102209

Csikszentmihalyi, M. (1990). Flow: The psychology of optimal experience. New York: Harper \& Row.

Delle Fave, A., Brdar, l., Freire, T., Vella-Brodrick, D., \& Wissing, M. P. (2011). The eudaimonic and hedonic components of happiness: Qualitative and quantitative findings. Social Indicators Research, 100(2), 185-207. https://doi.org/10.1007/s11205-010-9632-5

Desforges, L. (2000). Traveling the world; Identity and travel biography. Annals of Tourism Research, 27(4), 926 945. https://doi.org/10.1016/S0160-7383(99)00125-5

Diener, E. (1984). Subjective well-being. Psychological Bulletin, 95(3), 542-575. https://doi.org/10.1037/00332909.95.3.542

Erikson, E. H. (1972). Identidade, juventude e crise. Rio de Janeiro: Zahar.

Filep, S., \& Deery, M. (2010). Towards a picture of tourists' happiness. Tourism Analysis, 15(4), 399-410. https://doi.org/10.3727/108354210X12864727453061

Filep, S., \& Pearce, P. L. (2013). Tourist experience and fulfilment; Insights from positive psychology. New York: Routledge. p225. https://doi.org/10.4324/9780203134580

Filep, S., Laing, J., \& Csikszentmihalyi, M. (Eds.). (2017). Positive tourism. London: Routledge. p232. https://doi.org/10.4324/9781315707129

Frankl, V. E. (2016). Em busca de sentido. 39.Petrópolis: Vozes.

Gable, S. L., \& Haidt, J. (2005). What (and why) is positive psychology?. Review of General Psychology, 9(2), 103110. https://doi.org/10.1037/1089-2680.9.2.103

Gallagher, M. W., Lopez, S. J., \& Preacher, K. J. (2009). The hierarchical structure of well-being. Journal of Personality, 77(4), 1025-1050. https://doi.org/10.1111/i.1467-6494.2009.00573.x 
Hair Jr., J. F., Black, W. C., Babin, B. J., \& Anderson, R. E. (2014). Multivariate data analysis. 7. ed. United States: Pearson.

Hidalgo, J. L-T., Bravo, B. N., Martínez, I. P., Pretel, F. A., Postigo, J. M. L., \& Rabadán, F. E. (2010). Psychological well-being, assessment tools and related factors. In Wells, I. E. (Ed.). Psychological well-being. New York: Nova Science Publishers. 77-113.

Huppert, F. A., \& So, T. T. C. (2013). Flourishing across Europe: Application of a new conceptual framework for defining well-Being. Social Indicators Research, 110(3), 837-861. https://doi.org/10.1007/s11205-011-9966-7

Huta, V. (2016). Eudaimonic and hedonic orientations: Theoretical considerations and research findings. In Vitters $\emptyset$, J. (Ed.). Handbook of eudaimonic well-being. Switzerland: Springer. 215-231. https://doi.org/10.1007/978-3-319-42445-3 15

Huta, V., \& Ryan, R. M. (2010). Pursuing pleasure or virtue: The differential and overlapping well-being benefits of hedonic and eudaimonic motives. Journal of Happiness Studies, 11(6), 735-62. https://doi.org/10.1007/s10902-009-9171-4

Jahoda, M. (1958). Current concepts of mental health. New York: Basic Books. https://doi.org/10.1037/11258$\underline{000}$

Kashdan, T. B., Biswas-Diener, R., \& King, L. A. (2008). Reconsidering happiness: the costs of distinguishing between hedonics and eudaimonia. Journal of Positive Psychology, 3(4), 219-233. https://doi.org/10.1080/17439760802303044

Kernis, M. H., \& Goldman, B. M. (2006). A multicomponent conceptualization of authenticity: Theory and research. Advances in Experimental Social Psychology, 38, 283-357. https://doi.org/10.1016/S0065-2601(06)38006-9

Keyes C. L. M., \& Haidt, J. (Eds.). (2003). Flourishing: Positive psychology and the life well-lived. Washington, DC: APA. https://doi.org/10.1037/10594-000

Kim, H., \& Jamal, T. (2007). Tourist quest for existential authenticity. Annals of Tourism Research, 34, $181-201$. https://doi.org/10.1016/j.annals.2006.07.009

Kirillova, K., \& Lehto, X. (2015). An existential conceptualization of the vacation cycle. Annals of Tourism Research, 55, 110-123. https://doi.org/10.1016/j.annals.2015.09.003

Kirillova, K., Lehto, X., \& Cai, L. (2016a). Tourism and existential transformation: An empirical investigation. Journal of Travel Research, 56(5), 638-650. https://doi.org/10.1177/0047287516650277

Kirillova, K., Lehto, X., \& Cai, L. (2016b). Existential authenticity and anxiety as outcomes: The tourist in the experience economy. International Journal of Tourism Research, 19, 13-26. https://doi.org/10.1002/itr.2080

Kirillova, K., Lehto, X., \& Cai, L. (2017). What triggers transformative tourism experiences? Tourism Recreation Research, 42(4), 498-511. https://doi.org/10.1080/02508281.2017.1342349

Knoblock, U., Robertson, K., \& Aitken, R. (2016). Experience, emotion and eudaimonia: A consideration of tourist experiences and well-being. Journal of Travel Research, 56(5), 1-12. https://doi.org/10.1177/0047287516650937

Kontogeorgopoulos, N. (2017). Finding oneself while discovering others: An existential perspective on volunteer tourism in Thailand. Annals of Tourism Research, 65, 1-12. https://doi.org/10.1016/i.annals.2017.04.006

Kottler, J. A. (1998). Viajar como experincia transformadora; El viaje como desafío, crecimento personal, autorresponsabilidad, recorrido interior. Barcelona, Espanha: Paidós.

Kottler, J. A. (2002). Transformative travel: International counselling in action. International Journal for the Advancement of Counselling, 24(4), 207-210. https://doi.org/10.1023/A:1023364628260

Lean, G., Staiff, R., \& Waterton, E. (2014). Travel and Transformation. Australia: Ashgate.

Marcia, J. E. (1966). Development and validation of ego-identity status. Journal of Personality and Social Psychology, 3(5), 551-558. https://doi.org/10.1037/h0023281

Maslow, A. (1959). Cognition of being in the peak experiences. The Journal of Genetic Psychology, 94, 43-66. https://doi.org/10.1080/00221325.1959.10532434

Maslow, A. H. (1993). The farther reaches of human nature. New York, USA: Penguin Books.

Maslow, A. H. (s. d.). Introdução à psicologia do ser. Rio de Janeiro, Eldorado, s. d. Disponível em: <http://www.espacoseressencial.com/resources/Abraham\%20H.\%20Maslow\%20-\%20In-

trodu\%C3\%A7\%C3\%A30\%20\%C3\%A0\%20Psicologia\%20do\%20Ser.pdf> Acesso em: 19/03/2015

Matteucci, X., \& Filep, S. (2015). Eudaimonic tourist experiences: The case of flamenco. Leisure Studies, 36, 3952. https://doi.org/10.1080/02614367.2015.1085590 
Matteucci, X. (2013) Experiencing flamenco; An examination of a spiritual journey. In Filep, S., \& Pearce, P. L. (Eds.). Tourist experience and fulfilment; Insights from positive psychology. New York: Routledge. 110-126.

Neumann, M. (1992). The trail through experience: finding self in the recollection of travel. In Ellis, C., \& Flaherty, M. G. (Eds.). Investigating subjectivity; Research on lived experience. London: Sage. 176-201.

Newman, D. B., Tay, L., \& Diener, E. (2014). Leisure and subjective well-being: A model of psychological mechanisms as mediating factors. Journal of Happiness Studies, 15(3), 555-578. https://doi.org/10.1007/s10902013-9435-X

Norton, D. L. (1976). Personal destinies; A philosophy of ethical individualism. Princeton, NJ: Princeton University Press.

Noy, C. (2004). This trip really changed me; Backpackers' narratives of self-change. Annals of Tourism Research, 31, 78-102. https://doi.org/10.1016/i.annals.2003.08.004

Padilla-Walker, L. M., \& Nelson, L. J. (2017). Flourishing in emerging adulthood; Positive development during the third decade of life. New York: Oxford University Press. https://doi.org/10.1093/acprof:oso/9780190260637.001.0001

Peterson, C., \& Seligman, M. E. P. (2004). Character strengths and virtues: A handbook and classification. New York: Oxford University Press.

Reisinger, Y. (Ed.). (2013). Transformational tourism; Tourist perspectives. Oxfordshire, UK / Boston, USA: CABI. https://doi.org/10.1079/9781780642093.0000

Rickly-Boyd, J. (2012). Lifestyle climbing: Towards existential authenticity. Journal of Sport and Tourism, 17(2), 85-104. https://doi.org/10.1080/14775085.2012.729898

Roberson, D. N. (2009). The impact of travel on older ddults; an exploratory investigation. Disponivel em: <https://eric.ed.gov/?id=ED443996> Acesso em: 05/01/2018

Rogers, C. (2009). Tornar-se pessoa. 6. ed. São Paulo: Martins Fontes.

Ryan, R. M., \& Deci, E. L. (2000). Self-determination theory and the facilitation of intrinsic motivation, social development, and well-being. American Psychologist, 55, 68-78. https://doi.org/10.1037/0003-066X.55.1.68

Ryan, R. M., \& Deci, E. L. (2001). On happiness and human potentials: A review of research on hedonic and eudaimonic well-being. Annual Review of Psychology, 52, 141-66. https://doi.org/10.1146/annurev.psych.52.1.141

Ryan, R. M., \& Deci, E. L. (2017). Self-Determination Theory; Basic psychological needs in motivation, development and wellness. New York: The Guilford Press.

Ryan, R. M., \& Martela, F. (2016). Eudaimonia as a way of living: Connecting Aristotle with Self-Determination Theory. In Vitters $\varnothing$, J. (Ed.). Handbook of eudaimonic well-being. Switzerland: Springer. 109-122. https://doi.org/10.1007/978-3-319-42445-3 7

Ryan, R. M., Deci, E. L., Grolnick, W. S., \& La Guardia, J. G. (2006). The significance of autonomy and autonomy support in psychological development and psychopathology. In Cicchetti, D., \& Cohen, D. (Eds.). Developmental psychopathology: Theory and Methods, vol. 1, 2. ed. New York, John Wiley \& Sons. 295-849.

Ryff, C. D. (1989). Happiness is everything, or is it? Explorations on the meaning of eudaimonic well-being. Journal of Personality and Social Psychology, 57, 1069-1081. https://doi.org/10.1037/0022-3514.57.6.1069

Ryff, C. D., \& Keyes, L. M. (1995). The structure of psychological well-Being revisited. Journal of Personality and Social Psychology, 69(4), 719-727. https://doi.org/10.1037/0022-3514.69.4.719

Ryff, C. D., \& Singer, B. H. (1996). Psychological well-being: meaning, measurement, and implications for psychotherapy research. Psychotherapy and Psychosomatics, 65, 14-23. https://doi.org/10.1159/000289026

Ryff, C. D., \& Singer, B. H. (1998). The contours of positive human health. Psychological Inquiry, 9, 1-28. https://doi.org/10.1207/s15327965pli0901 1

Ryff, C. D., \& Singer, B. H. (2003). Flourishing under fire: Resilience as a prototype of challenged thriving. In Keyes C. L. M., \& Haidt, J. (Eds.). Flourishing: Positive psychology and the life well-lived. Washington, DC: APA. 15-36. https://doi.org/10.1037/10594-001

Ryff, C. D., \& Singer, B. H. (2008). Know thyself and become what you are: A eudaimonic approach to psychological well-being. Journal of Happiness Studies, 9, 13-39. https://doi.org/10.1007/s10902-006-9019-0

Salsman, J. M., Brown, T. L., Brechting, E. H., \& Carlson, C. R. (2005). The link between religion and spirituality and psychological adjustment: The mediating role of optimism and social support. Personality and Social Psychology Bulletin, 31, 522-535. https://doi.org/10.1177/0146167204271563 
Saunders, R. E., Laing, J., \& Weiler, B. (2013). Personal transformation through long-distance walking. In Filep, S. \& Pearce, P. L. (Eds.). Tourist experience and fulfilment; Insights from positive psychology. New York: Routledge. $127-146$.

Schlegel, R. J., Hicks, J. A., \& Christy, A. G. (2016). The eudaimonics of the true self. In Vitters $\emptyset$, J. (Ed.). Handbook of eudaimonic well-being. Switzerland: Springer. 205-213. https://doi.org/10.1007/978-3-319-42445-3_14

Seligman, M. E. P. (2002). Authentic happiness: Using the new positive psychology to realize your potential for lasting fulfillment. New York: Free Press.

Seligman, M. E. P. (2011). Florescer; uma nova compreensão sobre a natureza da felicidade e do bem-estar. Rio de Janeiro: Objetiva.

Sheldom, K. M., \& King, L. (2001). Why positive psychology is necessary. American Psychologist, 56(3), $216-217$. https://doi.org/10.1037/0003-066X.56.3.216

Sirgy, M. J., \& Uysal, M. (2016). Developing a Eudaimonia Research Agenda in Travel and Tourism. In Vittersø, J. (Ed.). Handbook of eudaimonic well-being, Switzerland: Springer, p. 485-495. https://doi.org/10.1007/978-3319-42445-3_32

Steger, M. F., Frazier, P., Oisho, S., \& Kaler, M. (2006). The Meaning in Life Questionnaire: Assessing the presence of and search for meaning in life. Journal of Counseling Psychology, 53, 80-93. https://doi.org/10.1037/00220167.53.1.80

Turner, V. W. (2013). O processo ritual. Petrópolis, Vozes.

Voigt, C., Brown, G., \& Howat, G. (2011). Wellness tourists: In search of transformation. Tourism Review, 66(1/2), 16-30. https://doi.org/10.1108/16605371111127206

Voigt, C., Howat, G., \& Brown, G. (2010). Hedonic and Eudaimonic Experiences among Wellness Tourists: An exploratory enquiry. Annals of Leisure Research, 13(3), 541-562. https://doi.org/10.1080/11745398.2010.9686862

Wang, N. (1999). Rethinking authenticity in tourism experience. Annals of Tourism Research, 26(2), 349-370. https://doi.org/10.1016/S0160-7383(98)00103-0

Waterman, A. S. (1984). Identity formation: Discovery or creation? Journal of Early Adolescence, 4(4), 329-341. https://doi.org/10.1177/0272431684044004

Waterman, A. S. (1990). Personal expressiveness: Philosophical and psychological foundations. Journal of Mind and Behavior, 11, 47-74.

Waterman, A. S. (1993). Two conceptions of happiness: Contrasts of personal expressiveness (eudaimonia) and hedonic enjoyment. Journal of Personality and Social Psychology, 64, 678-691. https://doi.org/10.1037/00223514.64.4.678

Waterman, A. S. (2004). Finding someone to be: studies on the role of intrinsic motivation in identity formation. Identity: An International Journal of Theory and Research, 4, 209-228. https://doi.org/10.1207/s1532706xid0403_1

Waterman, A. S. (2007). Doing well: The relationship of identity status to three conceptions of well-being. Identity: An International Journal of Theory and Research, 7, 289-308. https://doi.org/10.1080/15283480701600769

Waterman, A. S. (2008). Reconsidering happiness: A eudaimonist's perspective. Journal of Positive Psychology, 3 , 234-252. https://doi.org/10.1080/17439760802303002

Waterman, A. S., Schwartz, S. J., \& Conti, R. (2008). The implications of two conceptions of happiness (hedonic enjoyment and eudaimonia) for the understanding of intrinsic motivation. Journal of Happiness Studies, 9, 4179. https://doi.org/10.1007/s10902-006-9020-7

Waterman, A. S., Schwartz, S. J., Zamboanga, B. L., Ravert, R. D., Williams, M. K., Agocha, V. B., Kim, S. Y., \& Donnellan, M. B. (2010). The Questionnaire for Eudaimonic Well-Being: Psychometric properties, demographic comparisons, and evidence of validity. The Journal of Positive Psychology, 5, 41-61. https://doi.org/10.1080/17439760903435208

Wearing, S. (2001). Volunteer tourism: experiences that make a difference. London, CABI. https://doi.org/10.1079/9780851995335.0000

Wearing, S., \& McGehee, N. G. (2013). International volunteer tourism; integrating travellers and communities. Oxfordshire, UK / Boston, USA, CABI. https://doi.org/10.1079/9781845936969.0000

Wearing, S., Stevenson, D., \& Young, T. (2010). Tourist cultures, identity, place and the traveller. London/California/New Delhi/Singapore: Sage. 
Wood, A. M., Linley, P. A., Maltby, J., Baliousis, M., \& Joseph, S. (2008). The Authentic Personality: A theoretical and empirical conceptualization and the development of the Authenticity Scale. Journal of Counseling Psychology, 55(3), 385-399. https://doi.org/10.1037/0022-0167.55.3.385

Xue, L., Manuel-Navarrete, D., \& Buzinde, C. N. (2014). Theorizing the concept of alienation in tourism studies. Annals of Tourism Research, 44, 186-199. https://doi.org/10.1016/j.annals.2013.10.001

\section{Informações dos autores}

\section{Sandro Alves de Medeiros}

Graduado em Administração pelo Centro de Estudos Superiores de Maceió (1995), especialista em marketing pela ESPM (1999), mestrado em Administração pela UFAL (2005), doutorado em Administração pelo CEPEAD/UFMG (2018), professor do curso de turismo da Universidade Federal de Alagoas desde 2006.

Contribuições: concepção da pesquisa, revisão da literatura, coleta de dados, análise de dados, discussão dos resultados, revisão final do texto em português e em inglês.

E-mail: sandroamedeiros@gmail.com

ORCID: https://orcid.org/0000-0003-3927-0334

\section{Márcio Augusto Gonçalves}

Possui graduação em Engenharia Civil pela EEK/MG (1982), especialista em Análise de Sistemas pelo ICEx/UFMG (1986), mestrado em Administração pela Universidade Federal de Minas Gerais (1993) e PhD em Administração - Aston University (2002). Professor Associado do CEPEAD/UFMG. Coordena a Rede de Observatório de Custos em Saúde. Líder do Núcleo Observatório de Custos em Saúde - NOCES. Editor geral da Revista de Administração Hospitalar e Inovação em Saúde - RAHIS (ISSN 1983-5205). Coordenador do CEPEAD/UFMG 2013/2017.

Contribuições: concepção da pesquisa, análise de dados, discussão dos resultados.

E-mail: marcioag@face.ufmg.br

ORCID: https://orcid.org/0000-0003-2995-170X

\section{Ricardo Teixeira Veiga}

Graduado em Ciência da Computação pela Universidade Federal de Minas Gerais (1987), mestrado em Administração pela Universidade Federal de Minas Gerais (1993) e doutorado em Administração pela Universidade Federal de Minas Gerais (2000). Professor associado da Universidade Federal de Minas Gerais e professor colaborador do Centro de Estudos de Lazer e Recreação/UFMG. É membro do comitê editorial da Revista de Administração FACES e da Revista de Administração Hospitalar e Inovação em Saúde (RAHIS). É revisor da RAC. Revista de Administração Contemporânea, RAE. Revista de Administração de Empresas, BAR - Brazilian Administration Review, Management Research Review e de outros periódicos estrangeiros indexados. Coordena o NECC - Núcleo de Estatística e Ciências Comportamentais. Editor associado da revista BAR - Brazilian Administration Review (ISSN 1807-7692).

Contribuições: concepção da pesquisa, análise de dados, discussão dos resultados, revisão final do texto em português e em inglês.

E-mail: ricardo.necc@gmail.com

ORCID: https://orcid.org/0000-0001-5467-0972

\section{Giovana Barbosa Caraciolo:}

Graduada em Administração pela Faculdade de Alagoas/Estácio, e em Direito pelo Centro de Estudos Superiores de Maceió. Especialista em Direito.

Contribuições: coleta de dados, discussão dos resultados, revisão final do texto em português e em inglês, formatação do texto para publicação.

E-mail: giovana@gmail.com

ORCID: https://orcid.org/0000-0001-7140-3876 